\title{
LIMITE DA JUDICIALIZAÇÃO DA POLÍTICA: FUNDAMENTAÇÃO DAS DECISÕES JUDICIAIS SOB O PRISMA DA COMPREENSÃO HERMENÊUTICA DE FRIEDRICH MÜLLER
}

\section{LIMIT OF POLITCS JUDICIALIZATION: GROUNDS OF THE JUDICIAL DECISIONS AS A LIMIT OF THE INTERPRETATION OF THE CONSTITUTION IN THE CONSTITUTIONAL JURISDICTION}

Lucas Gonçalves da Silva

Pós-doutor em Direito pela Università Degli Studi G. d'Annunzio-UD'A (Itália). Pós-doutorando pela Universidade Federal da Bahia-UFBA. Doutor e Mestre em Direito do Estado pela PUC/SP. Professor Associado da Graduação em Direito e do Programa de Mestrado em Direito na Universidade Federal de Sergipe-UFS.

E-mail: lucasgs@uol.com.br

Ana Patricia Vieira Chaves Melo

Mestranda em Direito no Programa de Pós-Graduação da Universidade Federal de Sergipe. Pós-graduada em Direito Tributário pela Universidade do Sul de Santa Catarina. Promotora de Justiça do Ministério Público do Estado da Bahia.

E-mail: anapatricia.chaves@mpba.mp.br

Recebido em: 21/05/2018

Aprovado em: 01/03/2019

RESUMO: O norte substantivo da limitação da judicialização da política é a fundamentação constitucional rigorosa de suas decisões, como legitimador político das decisões judiciais, através de uma compreensão hermenêutica circular dos dados normativos e da realidade, num processo de concretização vinculado ao caso concreto, sob o paradigma do giro ontológico-linguístico operado em Heidegger e a fenomenologia hermenêutica de Müller. Limita-se o poder criativo dos juízes, para conferir controlabilidade jurídica e social das decisões judiciais, resguardar sua legitimidade democrática e promover a eficácia dos direitos fundamentais. Através de compreensão circular hermenêutica, com lastro em pesquisa bibliográfica, tratar-se-á do tema numa perspectiva da hermenêutica constitucional.

Palavras-chave: Judicialização da Política. Limites. Fundamentação das Decisões Judiciais. Hermenêutica. Interpretação.

ABSTRACT: The substantive north of the judicialization of politics' limitation is the strict constitutional grounds of its decisions, as a political legitimating of judicial decisions, through a circular hermeneutic understanding of normative data and reality, in a concretization process linked to the concrete case, under the paradigm of the ontological-linguistic turn operated in Heidegger and Müller's hermeneutic phenomenology. The creative power of judges is limited to confer legal and social controllability of judicial decisions, safeguard their democratic legitimacy 
and promote the effectiveness of fundamental rights. Through a circular hermeneutic understanding, based on bibliographical research, the subject will be treated in the perspective of constitutional hermeneutics.

Keywords: Judicialization of politics. Limits. Grounds of judicial decisions. Hermenenutics. Interpretation.

SUMÁRIO: Introdução. 1 A judicialização da política e o neconstitucionalismo. 2 Judicialização da política. 3 Limites da judicialização da política. Conclusão. Referências.

\section{INTRODUÇÃO}

A constitucionalização do direito ${ }^{1}$ ampliou os poderes e papel criativo do Poder Judiciário, de modo a conduzir à politização dos Tribunais e a uma sensação de insegurança jurídica. A função do Poder Judiciário de controle de constitucionalidade das leis e atos normativos produzidos pelo Executivo e Legislativo, de efetivação dos direitos fundamentais e de guardião da Constituição demanda a criação de normas jurídicas, tomando para si função que, segundo a divisão clássica dos poderes, pertencia ao Legislativo.

A judicialização da política e o ativismo judicial, por sua vez, suscitaram questionamentos e opiniões contrárias, haja vista a falta de legitimidade democrática dos juízes para realizar escolhas políticas, em suas decisões, quando exercem o controle judicial (MACHADO, 2012, p. 118). Essa oposição à judicialização da política e ao ativismo judicial se verificou nos países da América que adotaram o modelo difuso-concreto de controle de constitucionalidade das leis e estabeleceram uma Corte Suprema, inclusive o Brasil.

Faz-se necessária uma distinção entre os fenômenos, porquanto ativismo judicial e judicialização da política não se confundem. A judicialização da política ${ }^{2}$ decorre da redemocratização do país, que culminou com a promulgação da Constituição de 1988, da constitucionalização abrangente e do sistema de controle de constitucionalidade abrangente adotado no Brasil, que permitem que qualquer questão jurídica ou moralmente relavante seja levada à apreciação do Supremo (BARROSO, 2009, p. 17). Destarte, a judicialização não decorre da vontade do Judiciário, mas sim do constituinte (BARROSO, 2009, p. 17). Frise-se que a judicialização é gênero, de que são espécies judicialização da política e a judicialização do direito, implicando, respectivamente, transposição ao Judiciário de matérias até então deliberadas e decididas pelas instâncias políticas, e das relações sociais lato sensu, à apreciação e decisão do Judiciário (LEAL; ALVES, 2015, p. 6).

$\mathrm{O}$ ativismo judicial ${ }^{3}$, por sua vez, consiste em uma forma consciente, deliberada de exercício da jurisdição constitucional caracterizada pelo alargamento da aplicabilidade do texto

\footnotetext{
1 “[...] quando falamos em Constitucionalização do Direito estamos tratando da virada paradigmática ocorrida no Direito, e por conseguinte da sua interpretação para o pressuposto calcado nos ditames principiológicos do texto constitucional (SILVA, 2015, p. 126). A constitucionalização dos direitos compreendida como irradiação dos efeitos das normas constitucionais para outros ramos do direito, é um processo e, como tal, pode se revestir de diversas formas e pode ser promovida por diversos atores. No estudo deste fenômeno, destacam-se as análises de Schuppert e Bumke e de Luis Favoreu (SILVA, 2014, p. 38-39).

${ }^{2}$ Judicialização significa que algumas questões de larga repercussão política ou social estão sendo decididas por órgãos do Poder Judiciário, e não pelas instâncias políticas tradicionais: o Congresso Nacional e o Poder Executivo [...]. Como intuitivo, a judicialização envolve uma transferência de poder para juízes e tribunais, com alterações significativas na linguagem, na argumentação e no modo de participação da sociedade (BARROSO, 2009, p. 3).

${ }^{3}$ Ativismo judicial é uma expressão cunhada nos Estados Unidas da América para designar uma atuação proativa da Suprema Corte, em especial uma jurisprudência progressista em matéria de direitos fundamentais da Corte Warren,
} 
constitucional para abarcar casos não expressos; o abrandamento das exigências para a declaração de inconstitucionalidade; a definição de políticas públicas quando não há previsão constitucional de sua criação, mas apenas uma norma programática de eficácia limitada, de modo a interferir no espaço de discricionariedade do poder público quanto à forma de efetivação do direito social; e prolação de decisões cujo fundamento não é deduzido a um elemento normativo-constitucional. (GERVASONI, LEAL, 2013, p. 110). Enquanto o ativismo diz respeito a uma opção de postura da Corte Constitucional enquanto intérprete, a judicialização da política está associada a uma ampliação da atuação da jurisdição constitucional no contexto democrático (GERVASONI, LEAL, 2013, p. 111-112).

Destarte, transferência ao Judiciário de matérias até então decididas nas esferas políticas - judicialização da política - poderá acarretar um comportamento ativista, caracterizado por um comportamento proativo do Judiciário, em duas perspectivas: associado à interpretação constitucional e à interferência na esfera de atuação dos demais Poderes (LEAL; ALVES, 2015, p. 76).

No Brasil, pode-se afirmar, tal como Tocqueville (2002, p. 309), que raramente surge uma questão política que não é resolvida, cedo ou tarde, em uma questão judicial (TOCQUEVILLE, 2002, p. 309). Com efeito, questiona-se se tal poder criativo atribuído aos juízes pode se justificar em uma democracia e, em caso positivo, em quais limites pode ser exercido democraticamente.

Nesse diapasão, verificar-se-á se a fundamentação das decisões judiciais constitui norte substantivo à limitação judicialização da política operando como legitimador político das decisões judiciais. Com este desiderato, faz-se necessário, primeiramente, perscrutar a relação intrínseca entre neoconstitucionalismo e judicialização da política. A partir desse suporte teórico, verificar-se-á este fenômeno jurídico no contexto brasileiro. Nesse sentir, estabelecer-se-á norte substantivo para impor limites à judicialização da política, em um contexto de Estado Democrático de Direito.

Para tanto, utilizar-se-á uma compreensão hermenêutica circular, nos moldes preconizados por Frederich Müller ${ }^{4}$, baseada em pesquisa bibliográfica na doutrina nacional e estrangeira e na jurisprudência do Supremo Tribunal Federal sobre a judicialização da política e sua relação com a constitucionalização do direito e com o princípio da fundamentação das decisões judiciais, numa perspectiva constitucionalizante, com o fito de construir um quadro de referência teórica para traçar limites a este fenômeno jurídico.

\section{A JUDICIALIZAÇÃO DA POLÍTICA E O NECONSTITUCIONALISMO}

O conceito de "neoconstitucionalismo" - formulado sobretudo na Espanha e na Itália - não é unívoco, nem tampouco corresponde a uma concepção teórica coesa (SARMENTO,

entre 1954 e 1969. No entanto, em sua origem era uma expressão conservadora e nela “[...] se encontrou apoio para a política da segregação racial e para a invalidação das leis sociais em geral [...].” (BARROSO, 2015, p. 49). Frise-se que a judicialização facilita o ativismo, além de não ser vinculada ao caráter liberal ou conservador da Corte (GERVASONI, LEAL, 2013, p. 90-92).

${ }^{4}$ Criador da Teoria Estuturante da Norma, Frederich Müller supera a dicotomia Sujeito-objeto, entendendo que a interpretação não se dá linearmente - dos fatos à lei ou da lei aos fatos - mas circularmente, não metodologicamente, mas de forma histórica. Para o filósofo, "o círculo hermenêutico é um círculo rico em conteúdo, que reúne o intérprete e seu texto numa unidade interior a uma totalidade em movimento. A compreensão implica sempre uma précompreensão que, por sua vez, é pré-configurada por uma tradição determinada em que vive o intérprete e que modela seus preconceitos.” (GADAMER, 2008, p. 13). 
2009, p. 3). Por este motivo, Paolo Comanducci classifica, na linha utilizada por Bobbio em relação ao positivismo, em três diferentes formas de neoconstitucionalismo - teórico, ideológico e metodológico. Destaca que não se apresenta apenas como ideológica e correspondente metodologia, como também uma teoria concorrente com a positivista. (COMANDUCCI, 2002, 96-97). Adotam-se, neste artigo, os marcos propostos por Luís Roberto Barroso, quais sejam: a formação do Estado Constitucional de Direito como marco histórico; o marco filosófico do póspositivismo e como marco teórico a força normativa da constituição, o desenvolvimento de um nova dogmática de interpretação constitucional e expansão da jurisdição constitucional (BARROSO, 2015, p. 519-521). Segundo Eduardo Ribeiro Moreira, trata-se de uma teoria de direito lida a partir do direito constitucional, maximizada por elementos de filosofia de direito e de filosofia política, que permitem repensar os alicerces jurídicos: a teoria da norma, a teoria da interpretação, a teoria das fontes e, por fim, a constitucionalização do direito (MOREIRA, 2008, p. 250).

A constitucionalização do direito exsurgiu no Estado Constitucional de Direito, sob o influxo do pós-positivismo, caracterizado pela reaproximação entre ética e direito e pela centralidade dos direitos fundamentais. O principal aspecto desta irradiação dos efeitos das normas constitucionais aos outros ramos de direito consiste na vinculação da relação entre particulares a direitos fundamentais - a eficácia horizontal dos direitos fundamentais (SILVA, 2014, p. 14). Ao conferir um papel central aos direitos fundamentais, não somente nas dimensões subjetiva, mas também como valor da ordem jurídica objetiva - um sistema de valores válido para todo ordenamento jurídico - conforme preconizado pela doutrina e jurisprudências alemãs desde o caso Lüth", a constitucionalização dos direitos demanda uma "atuação mais incisiva do Judiciário, sob pena de termos uma Constituição repleta de direitos, mas que são negados a todo tempo pelo Poder que deveria assegurá-los." (GERVASONI, LEAL, 2013, p. 84).

No contexto do pós-positivismo, os princípios passaram a ter total hegemonia e preeminência. Paulo Bonavides assevera que, com o advento das Constituições da últimas décadas do século XX, os princípios converteram-se em pedestal normativo sob o qual se assenta todo o edifício jurídico dos novos sistemas constitucionais. Aponta, ainda, que "Essa posição de supremacia se concretizou com a jurisprudência dos princípios", especialmente no tocante à promoção da dignidade humana e dos direitos fundamentais. As constituições principiológicas, por sua vez, exigem atuação mais intensa da Justiça Constitucional substantiva ${ }^{6}-0$ controle jurisdicional da constitucionalidade (TAVARES, 2012, p. 40).

O fenômeno mundial da expansão da jurisdição constitucional conferiu maior relevância ao Poder Judiciário, infirmando sua concepção como legislador negativo, de modo a tornar inequívoco seu papel criativo do direito. Haja vista a submissão da lei à Constituição, inclusive no que tange aos direitos e garantias fundamentais, reconheceu-se que o magistrado exerce a função de criador de normas jurídicas individuais, ou como aponta Marinoni (2009, p.

\footnotetext{
${ }^{5}$ Nesse caso, considerado por muito o mais importante julgamento do Tribunal Constitucional Alemão, fundante da teoria dos efeitos indiretos dos direitos fundamentais na relação entre particulares, desenvolveu-se uma função complementar dos direitos fundamentais - a de sistema objetiva de valores, nos seguintes termos: "A Constituição, que não pretende ser uma ordem axiologicamente neutra, funda, no título dos direitos fundamentais, uma ordem objetiva de valores, por meio do qual se expressa um (...) fortalecimento da validade (...) dos direitos fundamentais. Esse sistema de valores, que tem seu ponto central no livre desenvolvimento da personalidade e na dignidade humana no seio da comunidade social, deve valer como decisão fundamental para todos os ramos do direito [...]" (SILVA, 2011, p. 42).

6 “A jurisdição constitucional legitimou-se, historicamente, pelo inestimável serviço prestado às duas idéias centrais que se fundiram para criar o moderno Estado democrático de direito: constitucionalismo (i.e., poder limitado e respeito aos direitos fundamentais) e democracia (soberania popular e governo da maioria).” (BARROSO, 2015, p. 50).
} 
21), criador de efetiva tutela de direitos, ainda que isso requeira o desconsiderar e/ou considerar parcial da lei.

No Brasil, a judicialização da política acentuou-se diante da desilusão com a política majoritária, em razão dos escândalos de corrupção e consequente crise de representatividade. A respeito deste fenômeno, Cappelletti aponta o declínio da confiança no parlamento como elemento característico de todo mundo ocidental (CAPPELLETTI, 1993, p. 45). Nesse contexto, o Poder Judiciário tomou para si as atribuições da interpretação normativa, com o escopo de resguardar os direitos fundamentais, passando a tomar decisões de conteúdo político e moral, inclusive em questões polêmicas. Destarte, a judicialização política - fenômeno mundial tornou tênue os limites entre política e direito, criação e interpretação do direito.

As resistências à judicialização da política estão intrinsicamente ligadas à hermenêutica jurídica. Ainda é disseminada a crença entre os juristas em dois mitos dos positivismos jurídico ${ }^{7}$ : a de completude do ordenamento jurídico e inevitabilidade de decisões discricionárias.

Não obstante as conquistas epistemológicas do positivismo jurídico e suas contribuições para a sistematização da teoria do direito, o pós-positivismo, sem desconsiderar que a lei é um tópos importante (POSNER, 1992, p. 436), busca acrescentar-lhe uma teoria de interpretação e da decisão judicial. Assim, demonstra-se a superação das concepções de Direito que limitam o direito à norma estatal produzida (SILVA; NASCIMENTO, 2015, p. 128).

Seja na escolas exegética francesa, seja na Jurisprudência dos Conceitos alemã, apresentava-se a lei como despicienda de interpretação. Todo esforço hermenêutico já teria sido feito pelo Legislador e, após um período de legitimidade das decisões sem fundamentação, a exigência de motivação foi introduzida na lei de organização judiciária da França 1790 como mecanismo de controle da magistratura, que, por estar ligada ao Antigo Regime, era vista com desconfiança pela burguesia (SCHMITZ, 2015, p. 53-54). Nesse contexto, concebeu-se o juiz como a "boca que pronuncia as palavras da lei"8, na expressão utilizada por Montesquieu (MOTESQUIEU, 2010, p. 175). De acordo com a cultura positivista, cabe ao juiz, num raciocínio lógico-dedutivo, aplicar a lei através de uma operação silogística. Da dicotomia entre fato e direito, exsurge a decisão, que reproduz o sentido unívoco já contido na lei.

Diferentemente das escolas exegéticas, Kelsen entende que a norma jurídica é uma moldura que admite diversas possibilidades de aplicação e que a construção da norma individual é ato subjetivo e relativo, insuscetível de controle (KELSEN, 1985, p. 247). Malgrado a Teoria Pura do Direito (KELSEN, 1985, p. 76) não desconheça a existência de valores e uma justiça relativa, extrai da ciência jurídica o que há de valorativo para o campo da moral ou política, colimando segurança jurídica. Para Kelsen, a interpretação e aplicação do direito estão fora dos limites da teoria do direito.

O pós-positivismo propugna por uma teoria da interpretação e da decisão judicial. Conforme exposto em outra oportunidade, "[...] é na interpretação constitucional com o apreço pelo bom funcionamento da ciência jurídica que a preocupação do estudioso/intérprete deve recair" (SILVA, 2015, p. 134). Destarte, os limites entre direito e política nas decisões judiciais é perpassado pelo problema hermenêutico de interpretação da Constituição.

\footnotetext{
${ }^{7}$ Positivismo exegético e normativista (SCHMITZ, 2015, p. 52).

8 “Consoante anota F. Callejón: A imposição da lei, é, assim, tão brutal que não deixa lugar algum para a construção teórica no primeiro positivismo, e menos ainda para a interpretação e criação do Direito fora dos limites da aplicação mecânica da lei." (TAVARES, 2014, p. 46-47).
} 


\section{JUDICIALIZAÇÃO DA POLÍTICA}

A judicialização da política é um fato irrefutável, decorrente do modelo de constitucionalização analítico e abrangente e do sistema de controle de constitucionalidade adotado no Brasil (BARROSO, 2015b, p. 442-443). Por outro lado, a forma como o Judiciário exercerá essa competência indicará a existência e o grau de ativismo judicial - associada a uma participação mais ampla e intensa do Judiciário na concretização dos valores e fins constitucionais, com maior interferência no espaço de atuação dos outros dois Poderes. A ideia de ativismo judicial, portanto, é proporcional ao grau de discricionariedade que se confere à atividade jurisdicional. No entanto, por vezes, camufla-se esse poder criativo de normas sob o manto da interpretação.

No âmbito da Suprema Corte, desenvolveram-se diversos âmbitos de judicialização da política: políticas governamentais, tais como a constitucionalidade de contribuição dos inativos e reforma do Judiciário; a relação entre os Poderes, ao julgar sobre os limites das Comissões Parlamentares de Inquérito e a constitucionalidade da investigação criminal pelo Ministério Público; direitos fundamentais, tais como limites à liberdade de expressão em caso de racismo e a possibilidade de progressão de regime em crimes hediondos (BARROSO, 2009, p. 50). Verifica-se, portanto, que há uma linha tênue entre política e direito.

Ademais, são inúmeros os precedentes de postura ativista do Supremo Tribunal Federal, tais como a de fidelidade partidária ${ }^{9}$ e da vedação ao nepotismo ${ }^{10}$; liberdade de expressão e discurso do ódio ${ }^{11}$, uso de algemas $^{12}$, possibilidade de união estável homoafetiva ${ }^{13}$, descriminalização do aborto em caso de fetos anencefálicos ${ }^{14}$, demarcação da reserva Raposa imposição Serra do $\mathrm{Sol}^{15}$, bem como imposição de condutas ou abstenções ao Poder Público, em caso de inércia (greve no serviço público ${ }^{16}$ e criação de municípios ${ }^{17}$ ) ou de políticas públicas insuficientes (direito à saúde ${ }^{18}$ ). Com efeito, o ativismo judicial é recorrente sobretudo na seara da tutela dos direitos fundamentais.

Haja vista a participação ativa do Poder Judiciário, em especial da Corte Constitucional, no processo político, subjacente ao neoconstitucionalismo, a doutrina tece críticas à possibilidade de o magistrado moldar a Constituição de acordo com as suas preferências políticas e valorativas, em detrimento daquelas do legislador eleito, apontando a existência de uma espécie de poder constituinte permanente (SARMENTO, 2009, p. 12). Aponta-se, assim, um excesso de discricionariedade judicial e questiona-se a legitimidade de certas intervenções da Justiça Constitucional, especialmente diante de decisões que geram insatisfação na mídia, no Governo e no âmbito político-partidário.

A esse respeito, Dworkin sustenta que o juiz nunca deve legislar, porquanto ao juiz não cabe produzir o Direito, mas somente dizer o Direto já existente (DWORKIN, 2010, p. 54-62). Outrossim, para este filósofo, a seara das políticas públicas é terreno proibido, reservado à legislatura eleita. Cappelletti, em contraposição, assevera ser manifesto o caráter acentuadamente

\footnotetext{
${ }^{9}$ ADI 5081(STF, 2015)

${ }^{10}$ ADC 12/DF (STF, 2008) e Súmula vinculante no 13 (STF, 2008) .

11 HC 82.424/RS (STF, 2004).

${ }^{12}$ HC 89.429/RJ e Súmula vinculante no 11 (STF, 2008).

${ }^{13}$ ADPF 132/RJ (STF, 2011) e ADI 4.277/DF (STF, 2011).

${ }^{14}$ ADPF 54/DF (2012).

${ }^{15}$ Pet. 3388/RR (STF, 2013).

${ }^{16}$ MI 670/ES (STF, 2007).

${ }^{17}$ ADI 2.240 (STF, 2007).

${ }^{18}$ RE 271286 AgR/RS (STF, 2000).
} 
criativo da atividade judiciária de intepretação e de atuação legislativa e dos direitos sociais (CAPPELLETTI, 1993, p. 42).

É certo que a judicialização da política justifica-se na seara dos direitos fundamentais e na proteção das próprias regras da democracia. Assim, não é possível excluir uma atuação do juiz constitucional ou ativismo, como implementador da Constituição e concretizador de direitos fundamentais. Em que pese não seja exclusiva sua função na implementação destes direitos, a sua competência para tanto decorre da opção do texto constituinte, o que se depreende de "institutos como o da ação direta de inconstitucionalidade por omissão, o mandado de injunção, além das cláusulas tradicionais que concedem ao STF e seus magistrados a guarda (final) da Constituição e o alocam como implementador da Constituição.” (TAVARES, 2012, p. 37). Ademais, é consequência inexorável das exigências fundamentais da pós-modernidade, econômicas, políticas, sociais e constitucionais. (CAPPELLETTI, p. 73).

Frise-se, ainda, que a judicialização das políticas, em especial das políticas públicas, propicia outorgar às normas de direitos fundamentais a maior eficácia possível no âmbito jurídico. Trata-se de fenômeno intrinsicamente ligado ao Estado Social, visto que, "após a positivação dos direitos sociais, seguiu-se um processo de positivação de suas garantias, o que leva a um processo de judicialização de tais direitos [...]” (FRISCHEISEN, 2000, p. 97).

No contexto da Segunda Modernidade ${ }^{19}$ ou Pós-Modernidade, redimensionaramse diversos conceitos, tais como o de Estado-nação, soberania nacional e separação dos poderes. A esse respeito, pontuou-se, em outra obra, que "[...] a globalização, o aumento da interdependência dos Estados e das economias, da diminuição das fronteira, do avanço das formas de comunicação, caracterizam esse momento contemporâneo, ou para alguns chamados de pós-moderno." (SILVA; NASCIMENTO, 2015, p. 134).

Após a Constituição de 1988, verificou-se crescente judicializacão das demandas coletivas, como consequência de positivação dos direitos sociais e suas garantias, de modo que o Judiciário assumiu papel central na concretização dos direitos fundamentais. O caráter promocional da legislação social transformou a própria função jurisdicional, visto que passou a exigir dos demais poderes o cumprimento do dever do Estado de intervir ativamente na esfera social. Nesse aspecto, Ana Paula de Barcellos pontua que a utilização intensiva pelos enunciados constitucionais e legais de princípios e conceitos abertos e indeterminados transfere ao Judiciário um amplo poder de dizer o que é o direito (BARCELLOS, 2014, p. 148). Diante disso, as escolhas judiciais demandam justificativas, sob pena de serem acusadas de arbitrárias e ilegítimas em um Estado Democrático de Direito.

Daniel Sarmento (2007, p. 33) adverte que muitos juízes, deslumbrados pela possibilidade de alcançar justiça através da aplicação dos princípios, passaram a negligenciar o seu dever de fundamentar racionalmente os seus julgamentos. Por conseguinte, não se deve descurar de impor limites à judicialização da política, sob pena de incorrer nos perigos do decisionismo judicial.

\footnotetext{
${ }^{19}$ Expressão cunhada por Ulrich Beck para se referir à Modernidade Reflexiva, caracterizada pela globalização e consequente superação da ideia de Estado nacional como contêiner de determinada sociedade, pela individualização da sociedade, pela superação da oposição entre natureza e sociedade e esvaziamento do conceito de sociedade de trabalho (BECK, 2003, p. 23).
} 


\section{LIMITES DA JUDICIALIZAÇÃO DA POLÍTICA}

Com o escopo de abordar os limites da judicialização da política, impende invocar as lições de Hart (1983, p. 123-144) acerca do pesadelo - jude made law - e o "nobre sonho" - a aplicação formalista do direito legislado, dois extremos de um fenômeno das decisões judiciais. Diante deste paradoxo, invoca-se a conclusão de Hart de que, na prática, os juízes às vezes descobrem e às vezes produzem o direito e o ato de interpretar - pressuposto do direito envolve tanto a criação quanto o descobrimento. E isso implica o risco de politizar os tribunais. No entanto, não se pode confundir o caráter político da jurisdição constitucional com uma atuação de cunho político (QUEIROZ, 2000, p. 284).

Segundo a análise de Hart, os juízes americanos, em especial no primeiro período de ativismo judicial, entre a Guerra Civil e a New Deal, sob o fundamento da due process clause, julgaram inconstitucional diversas legislações sociais e econômicas de bem-estar social, aplicando, de fato, doutrinas pessoais políticas e econômicas do laissez-faire, como se encontrassem, de modo imparcial, alguma solução já latente naquela cláusula, supostamente acima do nível da política (HART, 1983, p. 127). A fim de ilustrar a judicialização da política, Hart invoca a decisão da Suprema Corte de 1973, que eliminou completamente a secular legislação contra o aborto em diversos estados-membros da União, contrariando a opinião moral de grande parte da população, em nome do direito à privacidade, o qual não é mencionado em nenhum lugar da Constituição, mas foi lido no due process clause.

Diante deste paradoxo, invoca-se a conclusão de Hart de que, na prática, os juízes às vezes descobrem e às vezes produzem o direito e o ato de interpretar - pressuposto do direito envolve tanto a criação quanto o descobrimento. Logo, a decisão judicial deve ser proferida de acordo com os princípios e valores estabelecidos no sistema, os quais exercem um papel de constrangimento sobre a escolha judicial, consoante a leitura do "nobre sonho" de Karl Llewellyn (HART, 1983, p. 136).

A decisão judicial, em que pese tenha uma dimensão política, deve encontrar lastro em argumentos de princípio e não de política, aplicando-se a ideia de integridade de Dworkin $^{20}$. Com efeito, deve-se compreender a limitação da jurisdição no sentido de fundamentar as decisões judiciais com argumentos de princípio, os quais buscam resguardar e garantir direitos já estabelecidos pela Constituição (SCHMITZ, 2015, p. 202-203).

O fenômeno jurídico não é concretizado por um sentimento ou vontade do julgador. Deve-se combater o uso estratégico da jurisdição, quando o juiz, com base na preferência subjetiva por um determinado resultado, aplica ou não um enunciado de súmula ou interpreta a norma de uma ou outra maneira, sem motivar a decisão (SCHMITZ, 2015, p. 204).

No Brasil, a prática jurídica demonstra que é corrente a prolação de decisões cuja fundamentação bem se aplica a qualquer caso. Em diversas liminares, discorrem-se páginas a respeito dos seus requisitos legais, colacionam-se jurisprudências e não se despende um parágrafo sequer para apreciar o caso concreto. Outrossim, é corrente a aplicação de um dispositivo legal como fundamentação da decisão, sem proceder um esforço argumentativo, ocultando-se a sua ação criativa, sob o argumento de que o texto é claro. Reproduzem-se enunciados de súmula e julgados

\footnotetext{
${ }^{20}$ Dworkin diferencia política de princípio, in verbis: "Denomino 'política'que será aquele tipo de padrão que estabelece um objetivo a ser alcançado, em geral uma melhoria em algum aspecto econômico, político ou social da comunidade. Denomino 'princípio' um padrão que deve ser observado, não porque vá promover ou assegurar um situação econômica, política ou social considerada desejável, mas porque é uma exigência de justiça ou equidade ou alguma outra dimensão da moralidade." (DWORKIN, 2010, p. 36).
} 
como se fossem suficientes para fundamentar a decisão judicial, baseando-se na crença de que a súmula é a norma extraída do texto e pode ser aplicada de forma mecânica. Nesse aspecto, é mister lembrar que não há norma pronta a ser mecanicamente aplicada e que o processo hermenêutico sempre se faz necessário.

$\mathrm{Na}$ aplicação dos direitos fundamentais, dada sua natureza principiológica, os Tribunais rotineiramente invocam o princípio da proporcionalidade com fulcro na teoria de direitos fundamentais de Alexy, mormente nos casos em que não há regra expressa sobre a questão sub judice (ALEXY, 1997, p. 160-172). Nesses casos de judicialização da política e de ativismo judicial, ao aplicar o princípio da proporcionalidade e a técnica do sopesamento, constata-se, num processo silogístico, a existência de conflito de princípios, invoca-se o princípio da proporcionalidade, porém não se fundamenta a escolha ou a invalidação da norma. Virgílio Afonso da Silva enfatiza que a invocação da proporcionalidade na jurisprudência do $\mathrm{STF}^{21}$ é, não raramente, um recurso a um tópos, com caráter meramente retórico, e não sistemático. Com efeito, o silogismo é despido de fundamentação racional e estruturada, constituindo em raciocínio simplista e mecânico.

Diante dessas práticas, é inegável que se impõe a limitação da judicialização da política nos Tribunais em prol da democracia. Nesse aspecto, é mister ressaltar que, malgrado esta imponha limites àquela, não se constitui empecilho, com sustentam alguns escritores do tema ${ }^{22}$. Como afirma Mauro Cappelletti, "a 'orgia' da criatividade judiciaria [...] não seria menos perigosa do que a 'orgia' da legislação [...] (CAPPELLETI, 1993, p. 88). Acrescenta, ainda, que a acentuação da criatividade judiciária foi em larga medida consequência do crescimento dos próprios ramos políticos e da necessidade de promover um controle efetivo (CAPPELLETTI, 1993, p. 8990).

A judicialização da política deve realizar-se a partir de parâmetros a fim de não conduzir à ineficácia dos direitos fundamentais, pelo que todo sistema jurídico procurou estabelecer e aplicar certo limites à liberdade judicial, tanto processuais quanto substanciais (CAPPELLETTI, 1993, p. 25). Conforme pontua Cappelletti, "Discricionariedade não quer dizer necessariamente arbitrariedade, e o juiz, embora inevitavelmente criador de direito, não é necessariamente um criador completamente livre de vínculos". (CAPPELLETTI, 1993, p. 25).

É certo que o poder criativo da função judiciária não significa direito arbitrariamente criado pelo juiz do caso concreto, visto que está sujeito a limites substanciais, malgrado não de forma absoluta e completa. Ocorre que, na linha propugnada por Mauro Cappelletti, esses limites substanciais não são a nota distintiva da atividade judiciária - quando a atividade do juiz é livre para basear suas próprias decisões em preceitos vagos e não escritos da equidade - do papel do legislador (CAPPELLETTI, 1993, p. 26 e 74). Haja vista não haver, do ponto de vista substancial, diferença ontológica entre os processos de criação do direito legislativo e judicial - ambos são law-making processes, eles se distinguem pelo aspecto processual - o modo de criação judiciária em relação ao modo de criação legislativa.

Destarte, faz-se necessária uma fundamentação específica e consistente das questões de fato e de direito na decisão judicial a fim de estabelecer limites à judicialização da política ou, como afirma Hart (1983, p. 136), um constrangimento sobre a escolha judicial. Isso porque a motivação das decisões judiciais estabelece a conexão da atividade decisória com o caso concreto, promove a imparcialidade do juiz ao controlar sua discricionariedade, além de constituir elemento fundamental para o regular exercício do contraditório.

\footnotetext{
${ }^{21} \mathrm{HC} 76.060-40$ (STF, 1998).

${ }^{22}$ Por todos, Edinilson Donisete Machado. (2012, p. 153-158).
} 
A respeito do dever de motivar, sustenta-se, compartilhando o entendimento de Michele Taruffo, que o dever de motivar não é somente formal, consistente em palavras que acompanham o dispositivo afirmando os fatos se verificaram, mas sobretudo material, determinado por um raciocínio justificativo idôneo a demonstrar que aqueles enunciados podem ser considerados verdadeiros. Desta forma, a motivação propicia um controle intersubjetivo de validade e confiabilidade das decisões judiciais, de modo a superar a difundida concepção segundo a qual a motivação não seria outra coisa senão um discurso retórico-persuasivo (TARUFFO, 2012, p. 274)

A maneira de fundamentar as decisões judiciais deve-se pautar não em um método específico, que racionalize, posteriormente, uma compreensão que já ocorreu, incorrendo no que Müller denomina de cripto-argumentação - uso de argumentos pelo juiz para esconder convicções pessoais, opiniões politicas, argumentos não expressos, destinados a conferir uma falsa legitimidade e racionalidade às decisões (MÜLLER, 2013, p. 97-99). Deve-se pautar em uma compreensão circular hermenêutica, de modo a superar o esquema filosófico sujeito-objeto, consoante fenomenologia hermenêutica de Frederich Müller. Com efeito, a fundamentação "faz parte do círculo hermenêutico e, como princípio constitucional, ela é a própria explicitação do ato de moverse nesse círculo, constituindo a própria condição de possibilidade dele.” (MOTTA, p. 97).

Segundo Gadamer, compreensão, interpretação e aplicação constituem um processo unitário, integrantes do processo hermenêutico (GADAMER, 2008, p. 406-407). Assim, não há interpretação em abstrato, com o escopo de revelar o sentido unívoco da norma, para, posteriormente, aplicá-lo em um caso concreto através do silogismo, como propunham as correntes do positivismo. Assim, fundamentar não é explicitar a interpretação. Lênio Streck sintetiza a relação entre interpretação, compreensão e aplicação: "Interpretamos para aplicar o direito e, ao fazê-lo, não nos limitamos a interpretar (=compreender) os textos normativos, mas também compreendemos (=interpretamos) a realidade e os fatos aos quais o direito há de ser aplicado" (STRECK, 2012, p. $31)$.

A hermenêutica interpretativa proposta neste artigo para limitar a discricionariedade das decisões judiciais no contexto do fenômeno jurídico da judicialização da política tem por fundamento filosófico o giro ontológico-linguístico operado em especial por Heidegger e a superação das dualidades da metafísica da consciência (HEIDEGGER, 2006, p. 3455). A filosofia da consciência retira a essência das coisas do objeto e transfere para o sujeito cognoscente, tendo caráter subjetivista, assentado no pensamento humano. Pressupõe o esquema sujeito-objeto, presente no pensamento racional cartesiano do homem como fundamento último da compreensão do mundo, e revolucionada mas não superada por Kant, que entende o homem-sujeito como constituidor do sentido das coisas-objeto (KANT, 1980, p. 13).

Em Heidegger, por outro lado, o sujeito da subjetividade é substituído pelo "seraí", composto pelo um "ente" objetificado e por um "ser" ontológico, que compreende as coisas antecipadamente, sem se desvincular da sua própria facticidade e de sua história (HEIDEGGER, 2006, p. 38-40). Tendo como condições de possibilidade a historicidade e a linguagem, Heidegger desconstrói a subjetividade e a construção matemática do conhecimento. Por conseguinte, entendese que a interpretação é a manifestação de algo que já compreendemos (SCHMITZ, 2015, p. 4648).

Através da fenomenologia, são superadas as dicotomias da metafísica clássica, tais como as que se operam na ciência jurídica entre questões de fato e do direito, interpretação e aplicação, decidir e fundamentar (SCHMITZ, 2015, p. 45). Dentro da hermenêutica filosófica de Gadamer, a linguagem deixa de ser instrumento para a compreensão do mundo para ser constituidora do mundo. 
Sob o paradigma de uma compreensão hermenêutica circular de Müller, intérprete (sujeito) e objeto (leis e fatos) já não podem mais ser compreendidos separadamente, sem compromisso com a realidade e o mundo concreto. Assim, o sentido não fica adormecido na lei, mas é atribuído pelo intérprete durante o processo de compreensão. Superada a dicotomia entre teoria e realidade, a norma pós-positivista não é abstrata, um imperativo ou estrutura material existente, nem se confunde com texto normativo (MÜLLER, 2013, p. 54).

Segundo a Teoria Estruturante da Norma de Müller, norma é resultado da interpretação, é decisão que somente existe diante da facticidade concreta, que condiciona a existência da norma. Para a concretização da norma, o texto normativo configura o dado mais importante ao lado do caso a ser decidido juridicamente (MÜLLER, 2013, p. 55). Com efeito, não seria possível a prevalência de um argumento puramente juspolítico que não encontre qualquer base no texto normativo, "[...] Muito pelo contrário, o texto constitucional é necessariamente o ponto de partida de uma operação interpretativa válida" (SILVA, 2015, p. 136). Ambos são coconstitutivos da norma, pois ao mesmo tempo que a norma é aplicada ao caso, este é aplicado à norma (MÜLLER, 2008, p. 120 e 247). Müller explicita dois conceitos jurídicos essenciais para o controle da subjetividade nas decisões judiciais: programa normativo - gama linguística de possibilidades interpretativas do texto normativo - e âmbito normativo - facticidade concreta. Ambos tem por finalidade definir os limites reais de aplicação do direito. Essa teoria coaduna-se com a concepção de Direito e fenômeno jurídico adotada por Lucas Gonçalves da Silva em outra obra:

Entretanto, embora deixado claro que a concepção de Direito aqui aplicada vai muito além do direito como norma produzida pelo ente estatal, do Estado, este é imprescindível, sendo ao mesmo tempo fundante e fundado por ele. Em outras palavras, a necessidade de entender o fenômeno jurídico necessita da compreensão do Estado e das relações e interações sociais que coligiram para a formação desse Estado e dos paradigmas a serem aplicados pela ciência jurídica. Dessa forma, não pode se fazer um estudo pretensamente científico do Direito ignorando as matizes históricas e filosóficas do Estado criador e ao mesmo tempo produto dessa mesma ordem jurídica (SILVA; NASCIMENTO, 2015, p. 218).

Tendo por paradigma a Teoria Estruturante, o intérprete/aplicador não pode ter discricionariedade ou arbitrariedade no momento da compreensão, pois é condicionado pela facticidade (SCHMITZ, 2015, p. 73). Como já assentado em outra ocasião, "[...] com a teoria estruturante não se visa transformar um Estado de Direito em Estado Judiciário[...]" (SILVA; GUIMARÃES, 2014, p. 200). Compartilhando este entendimento, Lênio Streck assevera que o intérprete não está autorizado a atribuir sentidos de forma arbitrária, como se texto e norma estivessem separados (STRECK, 2012, p. 43).

$\mathrm{O}$ esquema de silogismo jurídico, que ainda permeia a mentalidade jurídica no país, transforma a compreensão em um esquema de solução jurídica de lógica formal, conferindo aparência de legitimidade a decisões baseadas em preferências pessoais. Ovídio Baptista adverte que a não superação do positivismo nos tornará "vítimas das mais variadas formas de arbitrariedade, cometidas em nome do que se imagina ser a imparcial aplicação da 'vontade da lei', em sentenças que, antes de alicerçarem-se em fundamentos válidos, ocultam as verdadeiras razões de decidir" (SILVA, 2008, p. 140-141).

A metódica dos cânones de interpretação da hermenêutica clássica - gramatical ou literal, exegética, teleológica, entre outras - constitui racionalização posterior de uma 
compreensão, envolvendo falsa argumentação para decisões judiciais discricionárias. Destarte, não é epistemologicamente adequada como motivação judicial (SCHMITZ, 2015, p. 113). O intérprete escolhe o método que lhe agrada para justificar seu subjetivismo. Frise-se que se correm tais riscos mesmo nas decisões pautadas em normas "claras e expressas", fora dos limites da judicialização da política. Trata-se de fenômeno inerente à interpretação e aplicação do direito.

A esse respeito, Schmitz assevera, com supedâneo na teoria estruturante da norma, que não é a vontade do legislador, nem a vontade da norma, nem mesmo exclusivamente a vontade do julgador que ditarão o conteúdo do direito, mas a junção desses elementos em constante relação com a realidade. Assim, o jurista, em um movimento circular hermenêutico, verifica se o âmbito normativo se amolda ou é relevante para o programa normativo, que, por sua vez, já foi elaborado em decorrência da facticidade apresentada pelo âmbito normativo (SCHMITZ, 2015, p. 71).

Frise-se que não é epistemologicamente coerente com o pós-positivismo a ideia de que se devem utilizar elementos extratextuais somente quando o ordenamento for omisso, na lacuna da lei (SCHMITZ, 2015, p. 206). Tais elementos não se circunscrevem aos casos de judicialização da política e de ativismo judicial. José Rodrigo Rodriguez leciona que textos normativos "abertos" não implicam maior espaço para manobras interpretativas. Significam, por outro lado, maior responsabilidade política no momento de reconstruir a história institucional daquele conceito jurídico, demandando um esforço argumentativo maior (RODRIGUEZ, 2013, 2008). Destarte, textos normativos fechados não significam maior segurança jurídica. Ao contrário, implicam maior risco de que sejam aplicados sem a necessária fundamentação e necessária correlação com o caso concreto, sob a alegação de sua clareza. Disfarçam-se, ainda, as escolhas subjetivas feitas pelo juiz.

Conclui-se, pois, que os temores em face da judicialização da política devem-se, em grande parte, à influência positivista ainda presente na doutrina e prática jurídica no Brasil e à aplicação da hermenêutica jurídica clássica. Por isso, impende ressaltar que, ainda quando há texto normativo claro e expresso, estabelecendo o programa e o âmbito normativo, faz-se necessário o ato de interpretação e compreensão. Cada norma jurídica é irrepetível (SCHMITZ, 2015, p. 71). Os textos normativos se descolam da intenção do legislador no momento da sua entrada em vigor e seu sentido muda conforme o substrato fático-valorativo que o fundamenta (PEREIRA, 2012, p. 15).

Deve-se respeitar, com maior rigor, o programa e âmbito normativo dos princípios jurídicos invocados por ocasião das decisões judiciais com conteúdo político, numa compreensão hermenêutica circular, vinculada à realidade concreta. Impende ressaltar que o controle sobre o magistrado é diretamente proporcional ao seu poder criativo a fim de combater o decisionismo judicial. Não significa isto que os juízes devem se sobrepor à primazia da lei, porém, como aponta Schmitz, o juiz neutro é uma ficção que não é conveniente ao próprio Direito, porquanto a neutralidade ideológica é uma forma velada de ideologia (SCHMITZ, 2015, p. 82). Nesse aspecto, Posner adverte que, nas áreas em que o juiz possui poder discricionário, as suas concepções filosóficas, religiosas, econômicas e políticas devem orientá-lo (POSNER, 1992, p. 45).

Assim, o dever de motivação será tanto mais intenso quanto mais aberto ou vago for o direito a ser aplicado (PIRES, 2014, p. 110), desempenhando os princípios um papel de constrangimento sobre a escolha judicial, conforme ensina Hart. É o que ocorre na seara da judicialização da política, área que demanda maior "consciência de aplicação do Direito enquanto construção teórica de proteção dos indivíduos do arbítrio estatal [...]” (SILVA, 2015, p. 135).

A fundamentação das decisões judiciais opera, portanto, como legitimador político das decisões judiciais, na medida em que permite um controle da atividade do juiz não só 
do ponto de vista jurídico, pelas partes do processo, como também um controle mais amplo por toda a coletividade (CINTRA; GRINOVER; DINAMARCO, p. 74).

\section{CONCLUSÃO}

A judicialização da política é fato, consequência inexorável do Estado Constitucional e Democrático, do modelo de controle de constitucionalidade e constitucionalização abrangente adotados. Ademais, a judicialização da política demonstra um potencial democrático e sensível às necessidades da população, notadamente na busca pela concretização dos direitos fundamentais e por garantir as regras e mecanismos de participação da própria democracia.

Por ser a Constituição uma opção política, constitui-se porta de entrada da política no Direito. Destarte, a interpretação das suas normas envolve decisões políticas relevantes, do que decorre a necessidade de uma decisão interpretativa justificada. Não se deve negar a judicialização da política para se escorar na legitimidade democrática do Poder Legislativo expondo uma compreensão racional-dedutiva de uma compreensão que já ocorreu na mente do intérprete, como se fosse a vontade unívoca da lei ou do legislador - poder constituído. Não se pode decidir para depois buscar fundamento, porquanto, sob o paradigma do giro ontológico-linguístico operado por Heidegger e a fenomenologia hermenêutica de Müller, decisão e fundamentação constituem momento único.

Com efeito, a legitimidade das decisões do Judiciário assenta-se em uma fundamentação constitucional rigorosa de suas decisões, através de uma compreensão hermenêutica circular dos dados normativos e da realidade, num processo de concretização vinculado ao caso concreto. Um maior rigor na fundamentação das decisões judiciais coaduna-se, pois, com o maior poder criativo atribuído ao juiz e importância política e social de suas decisões. Por conseguinte, adequadamente compreendida, a fundamentação das decisões judiciais constitui limite à judicialização da política na medida em que permite seu controle social e jurídico.

\section{REFERÊNCIAS}

ALEXY, Robert. Teoria de los derechos fundamentales. Tradução: Ernesto Garzón Valdés. Madrid: Centro de Estudios Constitucionales, 1997.

ÁVILA, Humberto. "Neoconstitucionalismo": entre a "ciência do direito" e o "direito da ciência". Revista Eletrônica de Direito do Estado, Salvador, n. 17, jan./mar. 2009. Disponível em: < http://www.direitodoestado.com.br/rede.asp>. Acesso em: 07 abr. 2018.

BARROSO, Luís Roberto. A razão sem voto: o supremo tribunal federal e o governo da maioria. Revista Brasileira de Políticas Públicas, v. 5, n. especial, p. 23-50, 2015.

BARROSO, Luís Roberto. Judicialização, ativismo judicial e legitimidade democracrática. Revista Eletrônica do Conselho Federal da OAB. 4. ed, jan/fev. 2009. Disponível em: < http://www.oab.org.br/editora/revista/users/revista/1235066670174218181901.pdf >. Acesso em: 31 mar. 2018.

BARROSO, Luís Roberto. Neoconstitucionalismo e constitucionalização do direito: o triunfo tardio do direito constitucional no Brasil. Revista de Direito Administrativo, Rio de Janeiro, v. 240, p. 1-42, jan. 
2015. Disponível em: <http://bibliotecadigital.fgv.br/ojs/index.php/rda/article/view/43618>. Acesso em: 02 abr. 2018.

BECH, Ulrich. Liberdade ou capitalismo: Ulrich Bech conversa com Johanne Wilms. São Paulo: ed. Unesp, 2003.

BRASIL. Supremo Tribunal Federal. ADC 12/DF. Relator: Ministro Carlo Britto, Brasília, 18 de dezembro de 2009. Disponível em: <

http://www.stf.jus.br/portal/jurisprudencia/listarJurisprudencia.asp?s1=\%28ADC\%24\%2ESCLA $\% 2 \mathrm{E}+\mathrm{E}+12 \% 2 \mathrm{ENUME} \% 2 \mathrm{E} \% 29+\mathrm{OU}+\% 28 \mathrm{ADC} \% 2 \mathrm{EACMS} \% 2 \mathrm{E}+\mathrm{ADJ} 2+12 \% 2 \mathrm{EACMS} \% 2 \mathrm{E} \% 2$ 9\&base=baseAcordaos\&url=http://tinyurl.com/atyqf9h>. Acesso em: 21 mar. 2018.

BRASIL. Supremo Tribunal Federal. ADI 2240/BA. Relator: Ministro Eros Grau, Brasília, 03 de agosto de 2007. Disponível em: < http://www.stf.jus.br/portal/jurisprudencia/listarJurisprudencia.asp?s1=\%28ADI\%24\%2ESCLA $\% 2 \mathrm{E}+\mathrm{E}+2240 \% 2 \mathrm{ENUME} \% 2 \mathrm{E} \% 29+\mathrm{OU}+\% 28 \mathrm{ADI} \% 2 \mathrm{EACMS} \% 2 \mathrm{E}+\mathrm{ADJ} 2+2240 \% 2 \mathrm{EACMS} \% 2$ E\%29\&base=baseAcordaos\&url=http://tinyurl.com/cr3a4a9>. Acesso em: 21 mar. 2018.

BRASIL. Supremo Tribunal Federal. ADI 4277/DF. Relator: Ministro Ayres Brito, Brasília, 05 de maio de 2011. Disponível em: < http://www.stf.jus.br/portal/jurisprudencia/listarJurisprudencia.asp?s1=\%28ADI\%24\%2ESCLA $\% 2 \mathrm{E}+\mathrm{E}+4277 \% 2 \mathrm{ENUME} \% 2 \mathrm{E} \% 29+\mathrm{OU}+\% 28 \mathrm{ADI} \% 2 \mathrm{EACMS} \% 2 \mathrm{E}+\mathrm{ADJ} 2+4277 \% 2 \mathrm{EACMS} \% 2$ E\%29\&base=baseAcordaos\&url=http://tinyurl.com/bftpsyu >. Acesso em: 21 mar. 2018.

BRASIL. Supremo Tribunal Federal. ADI 5081/DF. Relator: Ministro Roberto Barroso, Brasília, 18 de agosto de 2015. Disponível em: < http://www.stf.jus.br/portal/jurisprudencia/listarJurisprudencia.asp?s1=\%28ADI\%24\%2ESCLA $\% 2 \mathrm{E}+\mathrm{E}+5081 \% 2 \mathrm{ENUME} \% 2 \mathrm{E} \% 29+\mathrm{OU}+\% 28 \mathrm{ADI} \% 2 \mathrm{EACMS} \% 2 \mathrm{E}+\mathrm{ADJ} 2+5081 \% 2 \mathrm{EACMS} \% 2$ $\mathrm{E} \% 29 \&$ base=baseAcordaos\&url=http://tinyurl.com/po5jmun $>$. Acesso em: 21 mar. 2018.

BRASIL. Supremo Tribunal Federal. ADPF 54/DF. Relator: Ministro Marco Aurélio, Brasília, 12 de abril de 2012. Disponível em: < http://www.stf.jus.br/portal/jurisprudencia/listarJurisprudencia.asp?s1=\%28ADPF\%24\%2ESCL $\mathrm{A} \% 2 \mathrm{E}+\mathrm{E}+54 \% 2 \mathrm{ENUME} \% 2 \mathrm{E} \% 29+\mathrm{OU}+\% 28 \mathrm{ADPF} \% 2 \mathrm{EACMS} \% 2 \mathrm{E}+\mathrm{ADJ} 2+54 \% 2 \mathrm{EACMS} \% 2 \mathrm{E}$ \%29\&base=baseAcordaos\&url=http://tinyurl.com/a9mcpfe>. Acesso em: 21 mar. 2018.

BRASIL. Supremo Tribunal Federal. ADPF 132/RJ. Relator: Ministro Ayres Britto, Brasília, 05 de maio de 2011. Disponível em: < http://www.stf.jus.br/portal/jurisprudencia/listarJurisprudencia.asp?s1=\%28ADPF\%24\%2ESCL $\mathrm{A} \% 2 \mathrm{E}+\mathrm{E}+132 \% 2 \mathrm{ENUME} \% 2 \mathrm{E} \% 29+\mathrm{OU}+\% 28 \mathrm{ADPF} \% 2 \mathrm{EACMS} \% 2 \mathrm{E}+\mathrm{ADJ} 2+132 \% 2 \mathrm{EACMS} \%$ 2E\%29\&base=baseAcordaos\&url=http://tinyurl.com/avxgmj9>. Acesso em: 21 mar. 2018.

BRASIL. Supremo Tribunal Federal. HC 76060/SC. Relator: Ministro Sepúlveda Pertence, Brasília, 31 de março de 1998. Disponível em: < h http://www.stf.jus.br/portal/jurisprudencia/listarJurisprudencia.asp?s1=\%28HC\%24\%2ESCLA\% 2E+E+76060\%2ENUME\%2E\%29+OU+\%28HC\%2EACMS\%2E+ADJ2+76060\%2EACMS\%2E \%29\&base=baseAcordaos\&url=http://tinyurl.com/bvkt7nz >. Acesso em: 21 mar. 2018. 
BRASIL. Supremo Tribunal Federal. HC 82424/RS. Relator: Ministro Moreira Alves, Brasília, 19 de março de 2004. Disponível em: < http://www.stf.jus.br/portal/jurisprudencia/listarJurisprudencia.asp?s1=\%28HC\%24\%2ESCLA\% $2 \mathrm{E}+\mathrm{E}+82424 \% 2 \mathrm{ENUME} \% 2 \mathrm{E} \% 29+\mathrm{OU}+\% 28 \mathrm{HC} \% 2 \mathrm{EACMS} \% 2 \mathrm{E}+\mathrm{ADJ} 2+82424 \% 2 \mathrm{EACMS} \% 2 \mathrm{E}$ \%29\&base=baseAcordaos\&url=http://tinyurl.com/az3e35m>. Acesso em: 21 mar. 2018.

BRASIL. Supremo Tribunal Federal. HC 89429/RO. Relator: Ministro Carmem Lúcia, Brasília, 22 de agosto de 2006. Disponível em: < http://www.stf.jus.br/portal/jurisprudencia/listarJurisprudencia.asp?s1=\%28HC\%24\%2ESCLA\% 2E+E+89429\%2ENUME\%2E\%29+OU+\%28HC\%2EACMS\%2E+ADJ2+89429\%2EACMS\%2E \%29\&base=baseAcordaos\&url=http://tinyurl.com/c4qd2hh>. Acesso em: 21 mar. 2018.

BRASIL. Supremo Tribunal Federal. MI 670/ES. Relator: Ministro Gilmar Mendes, Brasília, 25 de outubro de 2007. Disponível em: < http://www.stf.jus.br/portal/jurisprudencia/listarJurisprudencia.asp?s1=\%28MI\%24\%2ESCLA\% 2E+E+670\%2ENUME\%2E\%29+OU+\%28MI\%2EACMS\%2E+ADJ2+670\%2EACMS\%2E\%29 \&base=baseAcordaos\&url=http://tinyurl.com/cswygf3>. Acesso em: 21 mar. 2018.

BRASIL. Supremo Tribunal Federal. Pet. 3388/RR. Relator: Ministro Roberto Barroso, Brasília, 23 de outubro de 2013. Disponível em: < http://www.stf.jus.br/portal/jurisprudencia/listarJurisprudencia.asp?s1=\%28Pet\%24\%2ESCLA\% 2E+E+3388\%2ENUME\%2E\%29+OU+\%28Pet $\% 2 \mathrm{EACMS} \% 2 \mathrm{E}+\mathrm{ADJ} 2+3388 \% 2 \mathrm{EACMS} \% 2 \mathrm{E} \%$ 29\&base=baseAcordaos\&url=http://tinyurl.com/a9vfyzn>. Acesso em: 21 mar. 2018.

BRASIL. Supremo Tribunal Federal. RE 271286 AgR/RS. Ministro Celso de Mello, Brasília, 24 de novembro de 2000. Disponível em: < http://www.stf.jus.br/portal/jurisprudencia/listarJurisprudencia.asp?s1=\%28RE\%24\%2ESCLA\% 2E+E+271286\%2ENUME\%2E\%29+OU+\%28RE\%2EACMS\%2E+ADJ2+271286\%2EACMS\% 2E\%29\&base=baseAcordaos\&url=http://tinyurl.com/ah6x5gl>. Acesso em: 21 mar. 2018.

BRASIL. Supremo Tribunal Federal. Súmula vinculante $\mathrm{n}^{\circ} 11$. Disponível em: < http://www.stf.jus.br/portal/jurisprudencia/menuSumario.asp?sumula=1220>. Acesso em: 21 mar. 2018.

BRASIL. Supremo Tribunal Federal. Súmula vinculante no 13. Disponível em: < http://www.stf.jus.br/portal/cms/verTexto.asp?servico=jurisprudenciaSumulaVinculante>. Acesso em: 21 mar. 2018.

CAPPELLETTI, MAURO. Juízes legisladores?. Tradução: Carlos Alberto Alvaro de Oliveira. Porto Alegre: Sérgio Antonio Fabris Editor, 1993.

CINTRA, Antônio Carlos de Araújo; GRINOVER, Ada Pellegrini; DINAMARCO, Cândido Rangel. Teoria geral do processo. 21. ed. São Paulo: Malheiros, 2010.

COSTA NETO, João. Liberdade de expressão: o conflito entre o legislador e o juiz constitucional. São Paulo: Saraiva Educação, 2017. 
DWORKIN, Ronald. Levando os direitos a sério. Tradução: Nelson Boeira. 3. ed. São Paulo: WMF Martins Fontes, 2010.

FRISCHEISEN, Luiza Cristina Fonseca. Políticas públicas: A responsabilidade do administrador e do ministério público. São Paulo: Max Limonad, 2000.

GADAMER, Hans-Georg. Verdade e métodos. Rio de Janeiro: Vozes, 2008.

GERVASONI, Tássia Aparecida; LEAL, Mônica Clarissa Hennig. Judicialização da política e ativismo judicial na perspectiva do supremo tribunal federal. Curitiba: Multideia, 2013.

HART, H. L. A.. American jurisprudence through english eyes: the nightmare and the noble dream. Essays in jurisprudence and philosophy, Oxford: Oxford University Press, 1983.

HEIDEGGER, Martin. Ser e tempo. Rio de Janeiro: Vozes, 2006.

KANT, Immanuel. Crítica da razão pura. São Paulo: Abril, 1980.

KELSEN, Hans. Teoria pura do direito. São Paulo: Martins Fontes, 1985.

LEAL, Mônica Clarissa Hennig; ALVES, Felipe Dalenogare. Judicialização e ativismo judicial: o supremo tribunal federal entre a interpretação e a intervenção na esfera de atuação dos demais poderes. Rio de Janeiro: Lumen Juris, 2015.

LEAL, Mônica Clarissa Hennig; ALVES, Felipe Dalenogare. A judicialização da política e do direito: um fenômeno decorrente de múltiplas causas, sob diferentes abordagens. Seminário Internacional de Demandas Sociais e Políticas Públicas na Sociedade Contemporânea. Rio Grande do Sul, UNISC: XI Seminário Internacional de Demandas Sociais e Políticas Públicas na Sociedade Contemporânea, VII Mostra de Trabalhos Jurídicos Científicos, 2014. Disponível em: < https://online.unisc.br/acadnet/anais/index.php/sidspp/article/download/.../1630 >. Acesso em: 13 mar. 2018.

MARINONI, Luiz Guilherme. Aproximação crítica entre as jurisdições da civil law e de common law e a necessidade de respeito aos precedentes no Brasil. Revista da Faculdade de Direito UFPR, Curitiba, v. 49, dez. 2009. Disponível em: <http://revistas.ufpr.br/direito/article/view/17031>. Acesso em: 31 mai. 2017.

MACHADO, Edinilson Donisete. Ativismo judicial: limites institucionais democráticos e constitucionais. 1. ed. São Paulo: Letras jurídicas, 2012.

MOREIRA, Eduardo Ribeiro. Neoconstitucionalismo e teoria da interpretação. Revista da EMERJ, Rio de Janeiro, v. 11, n. 43, p. 247-268, 2008. Disponível em: <http://www.emerj.tjrj.jus.br/revistaemerj_online/edicoes/revista43/Revista43_247.pdf>. Acesso em: 31 abr. 2018.

MOTTA, Cristina Reindeolff da. A motivação das decisões cíveis como condição de possibilidade para resposta correta/adequada. Porto Alegra: Livraria do advogado, 2012. 
MONTESQUIEU, Charles-Louis de Secondat. Do Espírito das leis. Trad.: Cristina Murachco. Martins Fontes, 2000.

MÜLLER, Frederich. O novo paradigma do direito. São Paulo: Revistas dos Tribunais, 2013.

MÜLLER, Frederich. Teoria estruturante do direito. São Paulo: Revistas dos Tribunais, 2008

PEREIRA, Hugo Filardi. Motivação das decisões judiciais e o estado constitucional. Rio de Janeiro: Lumen Juris, 2012.

POPPER, Karl. A lógica das ciências sociais. 3. ed. Rio de Janeiro: Tempo Brasileiro, 2004.

POSNER, Richard A. Legal reasoning from the top down and from the bottom up: the question of unenumerated constitutional rights. Chicago, 1992. Disponível

em: $\langle$ http://chicagounbound.uchicago.edu/cgi/viewcontent.cgi?article=2885\&context=journal_articles $>$. Acesso em 02 abr. 2018.

POSNER, Richard A. Para além do direito. Tradução: Evandro Ferreira e Silva. 3. ed. São Paulo: WMF Martins Fontes, 2009.

QUEIROZ, Cristina. Interpretação constitucional e poder judicial: sobre a epistemologia da construção constitucional. Coimbra: Coimbra, 2000.

RODRIGUEZ, José Rodrigo. Como decidem as cortes? São Paulo: FGV, 2013.

SARMENTO, Daniel. O neoconstitucionalismo no Brasil: riscos e possibilidades. Revista Brasileira de Estudos Constitucionais, Belo Horizonte, v. 3, n. 9, jan. 2009. Disponível em:

<http://bdjur.stj.jus.br/dspace/handle/2011/29044>. Acesso em: 20 mar. 2018.

SARMENTO, Daniel. Ubiquidade constitucional: Os Dois Lados da Moeda, Rio de Janeiro, 2007. Disponível em: <http://www.dsarmento.adv.br/content/3-publicacoes/17-ubiquidade-constitucional-osdois-lados-da-moeda/ubiquidade-constitucional-daniel-sarmento.pdf >. Acesso em: 15 abr. 2018.

SCHMITZ, Leonard Ziesemer. Fundamentação das decisões judiciais: a crise na construção de respostas no processo civil. São Paulo: Revista dos Tribunais, 2015.

SILVA, Lucas Gonçalves da; GUIMARÃES, Cecília Nogueira. A concretização dos direitos sociais e a atuação do Ministério Público sob o prisma da metódica constitucional de Friedrich Müller. In:ROBL FILHO, Ilton Norberto; MORAES FILHO José Filomeno de; SANTIN, Janaína Rigo (Org.). Teoria do estado e da constituição. 1. ed. Florianópolis: CONPEDI, v. 1, p. 194-208, 2014.

SILVA, Lucas Gonçalves da; NASCIMENTO, Leonardo Lessa Prado. A Constitucionalização do direito como paradigma para a ciência jurídica: o necessário cuidado para com algumas armadilhas do neoconstitucionalismo brasileiro. In: COUTINHO, Júlia Maia de Meneses; PASSOS, Daniela Veloso Souza (Org.). Temas do pensamento Constitucional Brasileiro. 1. ed. Belo Horizonte: Arraes Editores, v. 4, p. 125-139, 2015.

SILVA, Ovídio A. Baptista da. Jurisdição, direito material e processo. Rio de Janeiro: Forense, 2008, p. $140 / 141$. 
SILVA, Virgílio Afonso da. A constitucionalização do direito: os direitos fundamentais nas relações entre particulares. 1. ed., $4^{\mathrm{a}}$ tiragem. São Paulo: Malheiros, 2014.

STRECK, Lenio Luiz. Verdade e consenso. São Paulo: Saraiva, 2012.

STRECK, Lenio Luiz. Jurisdição constitucional e hermenêutica: uma nova crítica do Direito. Porto Alegre: Livraria do Advogado, 2002.

TARUFFO, Michele. Uma simples verdade: o juiz e a construção dos fatos. Trad. Vitor de Paula Ramos. São Paulo: Marcial Pons, 2012.

TAVARES, André Ramos. Curso de direito constitucional. 12 ed. São Paulo: Saraiva, 2014.

TAVARES, André Ramos. Paradigmas do judicialismo constitucional. São Paulo: Saraiva, 2012.

TOCQUEVILLE, Alexis de. Democracy in America. Chicago, 2002. Disponível em: < http://seas3.elte.hu/coursematerial/LojkoMiklos/Alexis-de-Tocqueville-Democracy-in-America.pdf>. Acesso em: 10 abr. 2018. 